Chest injury protocol (ChIP) IMPLEMENTATION STRATEGY

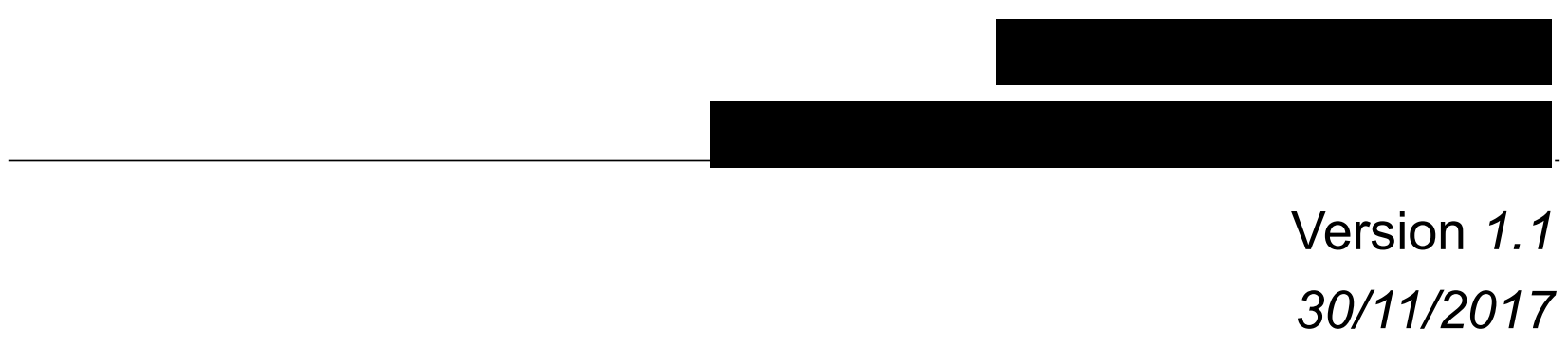




\section{VERSION HISTORY}

\begin{tabular}{|c|c|c|c|c|c|}
\hline Version \# & $\begin{array}{c}\text { Implemented } \\
\text { By }\end{array}$ & $\begin{array}{c}\text { Revision } \\
\text { Date }\end{array}$ & $\begin{array}{c}\text { Approved } \\
\text { By }\end{array}$ & $\begin{array}{c}\text { Approval } \\
\text { Date }\end{array}$ & Reason \\
\hline 1.0 & & $6 / 11 / 17$ & & $6 / 11 / 17$ & \\
\hline 1.1 & & $30 / 11 / 17$ & & $30 / 11 / 17$ & updated to do \\
\hline & & & & & \\
\hline
\end{tabular}




\section{Table of Contents}

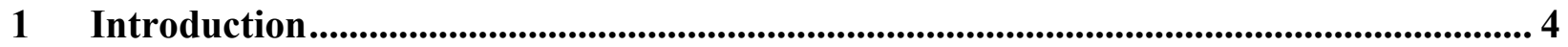

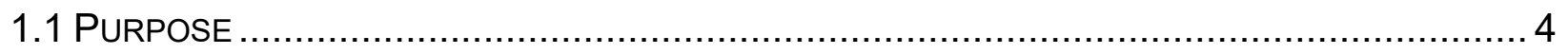

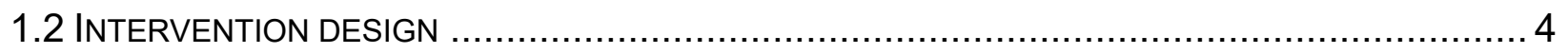

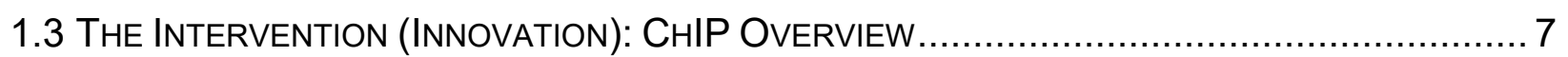

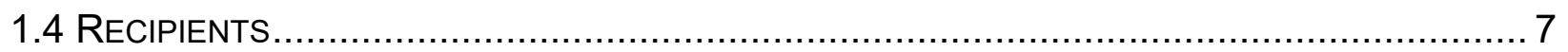

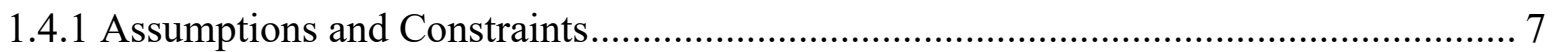

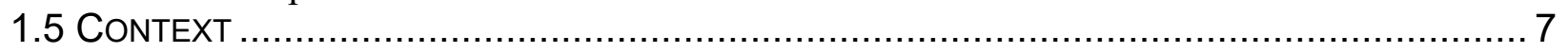

2 Management Overview................................................................................................................. 7

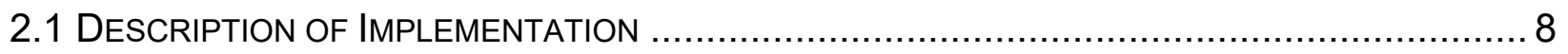

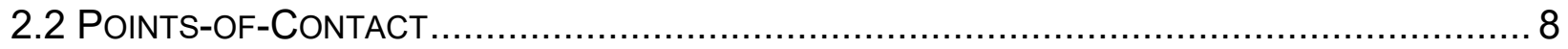

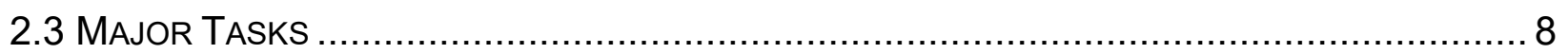

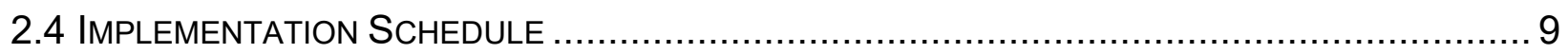

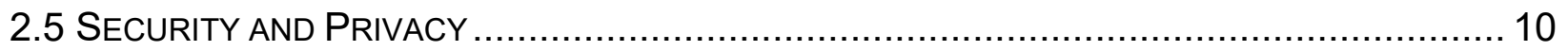

3 Implementation Support ................................................................................................................. 10

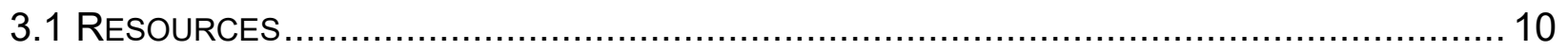

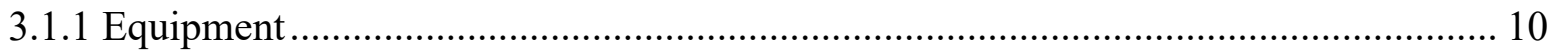

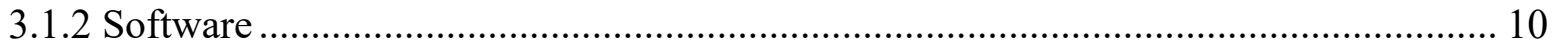

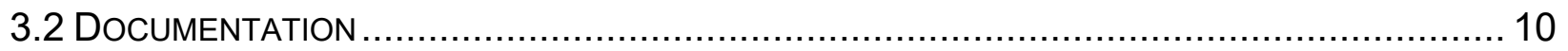

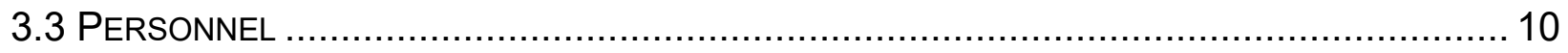

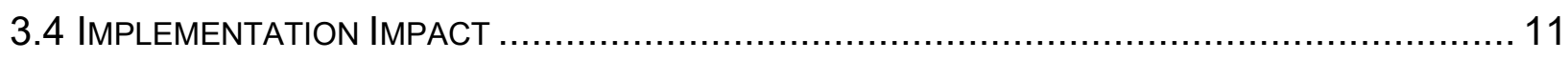

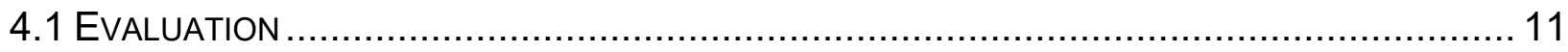

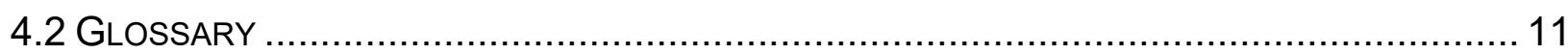

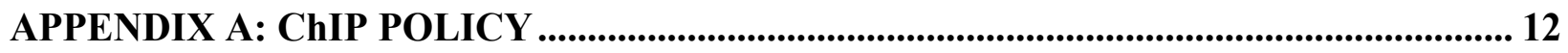

APPENDIX B: Stakeholders* ......................................................................................... 16

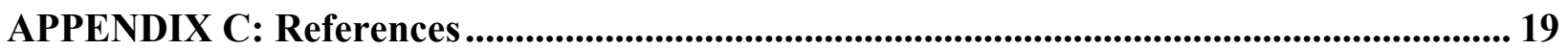




\section{Introduction}

\subsection{Purpose}

The purpose of this document is to outline a plan for the implementation of a Chest Injury care bundle protocol (ChIP) for The Hospitals respectively).

This document is part of a larger plan to more widely test and implement ChIP (Figure 1).

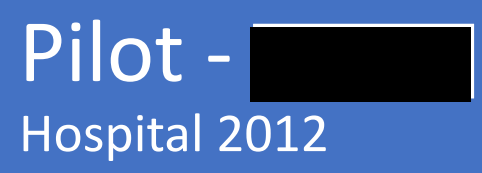

\section{Refinement of ChIP as a care} bundle

\section{Implement and test in another site - Implementation Plan}

Figure 1: Overall process of ChIP testing and implementation

\subsection{Intervention design}

Table 1: Implementation Overview

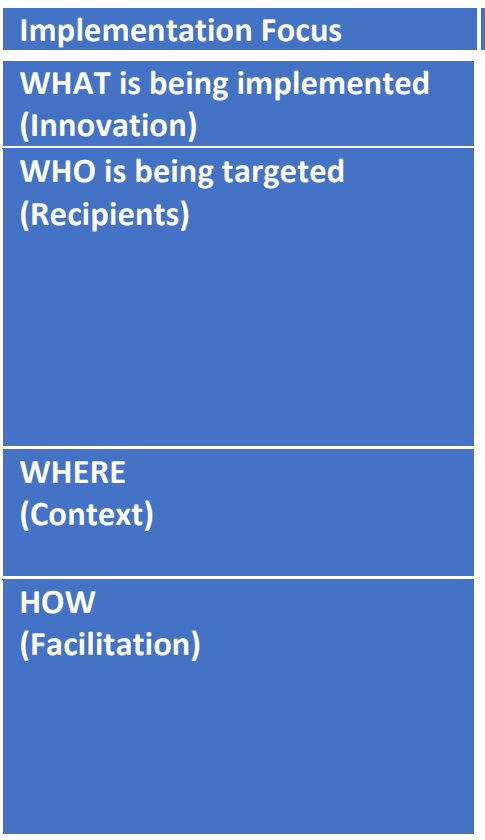

(Harvey \& Kitson, 2016)

\section{Elements of the intervention}

Evidence-based guidelines for blunt chest injury (ChIP)

Overarching aim: reduce pneumonia rates in blunt chest injury patients

Staff activating and responding to ChIP:

Surgical teams

Pain/Anaesthetic teams

Emergency department staff

Physiotherapists

Admissions staff

Ward staff

Acute health care setting:

Activated in emergency department

Local context assessment

Facilitation teams: external/internal expert and novice facilitators, clinical

leaders, project manager and information specialist

Tailored facilitation support at the individual team level

Learning resources from Fisher and Paykel

Development of audit 
Behaviour change theories support this implementation. The Behaviour Change Wheel was used in conjunction with the Theoretical Domains Framework (TDF) (Figure 2) (Rycroft-Malone, 2004). This was to support the implementation further ensuring that intervention strategies would be appropriate for behaviour change to occur.

A survey of staff has been undertaken to inform the implementation process. The survey was based on the 14 domains of the TDF. Through mapping to the TDF, the survey has identified facilitators and barriers to implementation.

Intervention strategies were then identified in a step-by-step process to find intervention functions and policy changes that would need to occur for change to occur. The APEASE criteria (Affordability, Practicability, Effectiveness and cost-effectiveness, Acceptability, Side-effects and safety, and Equity) was used to identify if interventions were suitable for implementation. The resulting plan is in Table 2.

Sources of behaviour

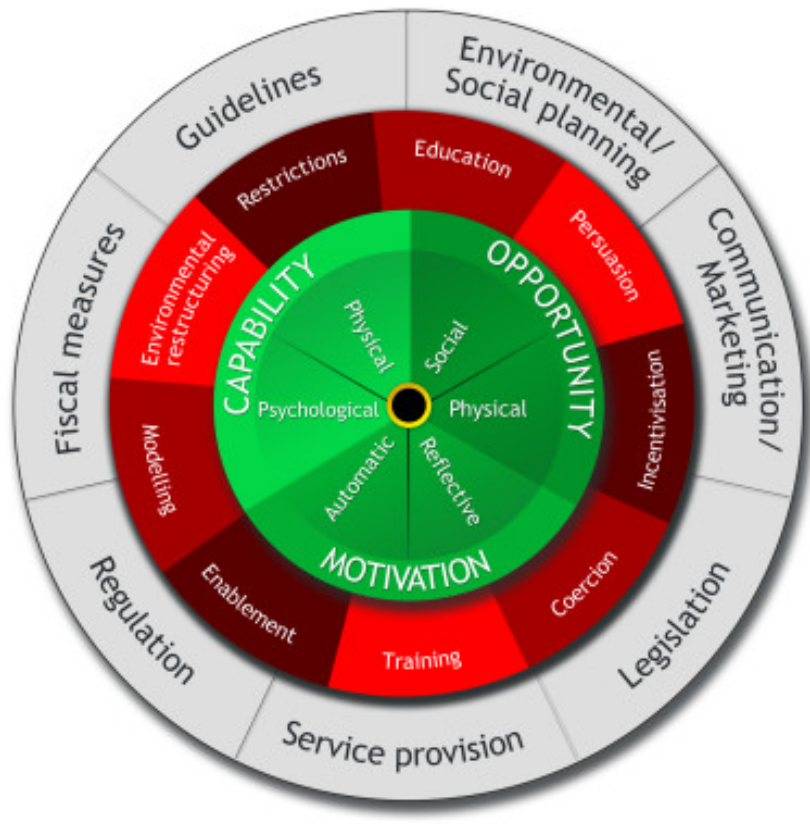

Figure 2. The behaviour change wheel with intervention functions and policy categories (Michie, van Stralen, \& West, 2011) 
Table 2.

\begin{tabular}{|c|c|c|c|c|}
\hline $\begin{array}{l}\text { Intervention } \\
\text { functions }\end{array}$ & $\begin{array}{l}\text { TDF components } \\
\text { served by } \\
\text { intervention } \\
\text { functions }\end{array}$ & $\begin{array}{l}\text { BCTs to deliver } \\
\text { intervention functions }\end{array}$ & $\begin{array}{l}\text { Policy categories } \\
\text { through which } \\
\text { BCTs can be } \\
\text { delivered }\end{array}$ & Intervention strategy \\
\hline $\begin{array}{l}\text { Education } \\
\text { Persuasion, } \\
\text { Incentivisation, } \\
\text { Training, } \\
\text { environmental } \\
\text { restructuring, } \\
\text { modelling, } \\
\text { enablement, }\end{array}$ & $\begin{array}{l}\text { Physical skills } \\
\text { Knowledge } \\
\text { Memory, attention } \\
\text { and decision } \\
\text { processes } \\
\text { Professional/ social } \\
\text { role and identity } \\
\text { Beliefs about } \\
\text { consequences } \\
\text { Emotion } \\
\text { Environmental } \\
\text { context and } \\
\text { resources } \\
\text { Social influences }\end{array}$ & $\begin{array}{l}\text { Information about } \\
\text { health consequences } \\
\text { Feedback on behaviour } \\
\text { Prompts/cues } \\
\text { Feedback on } \\
\text { outcome(s) of } \\
\text { behaviour } \\
\text { Information about } \\
\text { others' approval } \\
\text { Credible source } \\
\text { Verbal persuasion } \\
\text { about capability } \\
\text { Identification of self as } \\
\text { role model } \\
\text { Material reward } \\
\text { (outcome) - pizza } \\
\text { party } \\
\text { Incentive (outcome) } \\
\text { Commitment } \\
\text { Demonstration of } \\
\text { behaviour } \\
\text { Instruction on how to } \\
\text { perform behaviour } \\
\text { Habit formation } \\
\text { Adding objects to the } \\
\text { environment } \\
\text { Restructuring the } \\
\text { Shysical environment } \\
\text { Support }\end{array}$ & $\begin{array}{l}\text { Communication/ } \\
\text { marketing, } \\
\text { guidelines, } \\
\text { regulation, } \\
\text { environmental/soci } \\
\text { al planning }\end{array}$ & 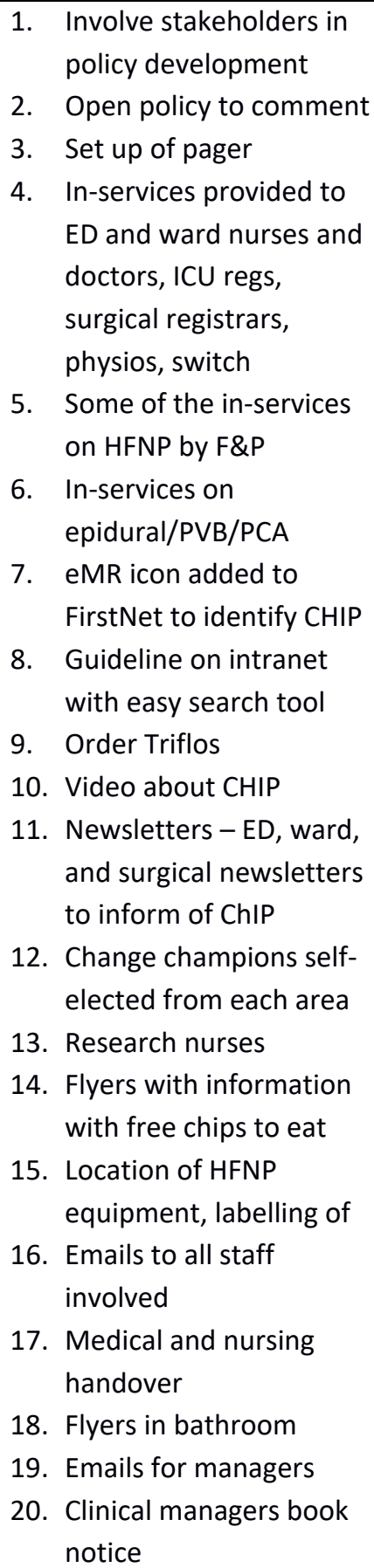 \\
\hline
\end{tabular}




\subsection{The Intervention (Innovation): ChIP Overview}

ChIP is a care bundle of evidenced-based interventions for patients with a mild-moderate blunt chest injury $(\mathrm{BCl})$. It aims to improve the outcomes of patients with blunt chest injury. ChIP has been used at another hospital resulting in a reduction in pneumonia by $56 \%$

. The protocol has been refined with a literature review of interventions for blunt chest injury. The protocol can be found in Appendix A.

\subsection{Recipients}

The people involved in the implementation of this intervention are staff members who are involved in the activation and response to ChIP. This includes:

- Emergency nurses, doctors and clerical staff

- Surgical doctors

- Anaesthetics doctors

- Ward nurses caring for patients with BCI

- Physiotherapists

- Switchboard staff

- ICU liaison nurse

- ICU doctors

- Pain team

To ensure adequate involvement of recipients a survey of these staff was conducted.

\subsubsection{Assumptions and Constraints}

Stakeholders have been consulted before development of this plan, and it is assumed that their support will continue for the implementation process. All stakeholders will be consulted in the development process to increase the sense of ownership (Harvey \& Kitson, 2016).

\subsection{Context}

The Hospitals 1 respectively) are the two sites where ChIP will be implemented. They are both within the same local health district (

\section{Management Overview}

The responsibility of management will lie with the emergency clinical nurse consultants (medical) and $\begin{gathered}\text { Executive sponsors are Critical Care Co-Directors } \\ \text { and }\end{gathered}$ Emergency services - service lead
and Major tasks for management include:

- Communication with key stakeholders

- Review and approval of policy 


\subsection{Description of Implementation}

ChIP will go live in both sites on the same day on $22^{\text {nd }}$ November 2017 . The activation system through the communications team will be active from one week before (15/11/17).

Intervention Strategies are:

1. Involve stakeholders in policy development

2. Open policy to comment

3. Set up of pager

4. In-services provided to ED and ward nurses and doctors, ICU regs, surgical registrars, physios, switch

5. Some of the in-services on HFNP by F\&P

6. In-services on epidural/PVB/PCA

7. eMR icon added to FirstNet to identify CHIP

8. Guideline on intranet with easy search tool

9. Order Triflos

10. Video about CHIP

11. Newsletters - ED, ward, and surgical newsletters to inform of ChIP

12. Change champions self-elected from each area

13. Research nurses

14. Flyers with information with free chips to eat

15. Location of HFNP equipment, labelling of

16. Emails to all staff involved

17. Medical and nursing handover

18. Flyers in bathroom

19. Emails for managers

\subsection{Points-of-Contact}

Stakeholders have been included from all areas involved, and a full list can be found in Appendix B.

\subsection{Major Tasks}

- Provide overall planning and coordination for the implementation

- Provide appropriate training for personnel

- Ensure that all manuals applicable to the implementation effort are available when needed

- Provide all needed technical assistance

- Schedule any special computer processing required for the implementation

- Perform site surveys before implementation

- Ensure that all prerequisites have been fulfilled before the implementation date

- Prepare site facilities for implementation

- Identifying and engaging with key stakeholders 


\subsection{Implementation Schedule}

\begin{tabular}{|c|c|c|c|}
\hline Task & Plan date by & Team member & $\begin{array}{l}\text { Date } \\
\text { completed }\end{array}$ \\
\hline Stakeholders approve policy & $14 / 8 / 17$ & & $20 / 11 / 17$ \\
\hline $\begin{array}{l}\text { Policy submitted for general online } \\
\text { comment }\end{array}$ & $15 / 10 / 17$ & & $18 / 10 / 17$ \\
\hline Organise set up the ChIP pager & $1 / 11 / 17$ & & $20 / 11 / 17$ \\
\hline $\begin{array}{l}\text { Organise dates and instructor (e.g. ICU } \\
\text { liaison, research nurses) for In-services } \\
\text { for CHIP: } \\
\text { Wards } \\
\text { ICU } \\
\text { ED } \\
\text { Surgical registrars } \\
\text { Anaesthetics } \\
\text { Physiotherapists }\end{array}$ & $20 / 11 / 17$ & & $31 / 10 / 17$ \\
\hline $\begin{array}{l}\text { Development of training materials (update } \\
\text { PPT) }\end{array}$ & $15 / 11 / 17$ & & $30 / 10 / 817$ \\
\hline $\begin{array}{l}\text { Guideline on the intranet with easy search } \\
\text { option }\end{array}$ & $1 / 11 / 17$ & & In progress \\
\hline Order TRIFLOs & $15 / 11 / 17$ & & Done \\
\hline $\begin{array}{cc}\text { Education for HFNP from F\&P } \\
-\quad \text { Discuss with F\&P } \\
-\quad \text { Organise times }\end{array}$ & $15 / 11 / 17$ & & $20 / 11 / 17$ \\
\hline Flyers for ED & $1 / 11 / 17$ & & $30 / 10 / 17$ \\
\hline $\begin{array}{l}\text { Get chips packets to go with flyers in tea } \\
\text { room }\end{array}$ & $15 / 11 / 17$ & & $30 / 10 / 17$ \\
\hline Ensure HFNP marked with instructions & $1 / 11 / 17$ & & $23 / 10 / 17$ \\
\hline EMR icon & $1 / 11 / 17$ & & $16 / 10 / 17$ \\
\hline Hire Casual research nurses & $1 / 11 / 17$ & & $\begin{array}{l}\text { Contracts } \\
\text { issued } \\
31 / 10 / 17\end{array}$ \\
\hline $\begin{array}{l}\text { Research nurses informed of roles and } \\
\text { can start championing process }\end{array}$ & $15 / 11 / 17$ & & $10 / 11 / 17$ \\
\hline
\end{tabular}




\begin{tabular}{|c|c|c|}
\hline $\begin{array}{c}\text { Video } \\
\text { - } \text { Get video footage } \\
\text { - Put it together }\end{array}$ & $1 / 11$ & Complete \\
\hline $\begin{array}{l}\text { Email to managers } \\
-\quad \text { Checking if being implemented } \\
-\quad \text { Audit }\end{array}$ & 20/11/17 & progress \\
\hline $\begin{array}{l}\text { Email to staff } \\
\text { - Draft email for each area list them } \\
\text { here }\end{array}$ & 20/11/17 & 20/11/17 \\
\hline $\begin{array}{l}\text { Notice for Newsletters } \\
-\quad \text { Surgical newsletter } \\
\text { - } \quad \text { EDs }\end{array}$ & 15/11/17 & $\begin{array}{l}\text { Surg NL } \\
30 / 10\end{array}$ \\
\hline notice & 20/11/17 & 20/11/17 \\
\hline
\end{tabular}

\subsection{Security and Privacy}

There are no breaches in security or privacy of patients or staff forseen by the implementation of ChIP.

\section{Implementation Support}

\subsection{Resources}

\subsubsection{Equipment}

Limited high flow nasal prong (HFNP) sets are available. However, eight sets are being provided by Fisher and Paykel for use in the implementation which should suffice. However, not all staff are familiar with HFNP use and may need training in this area. Fisher and Paykel have kindly agreed to provide training support in this area.

\subsubsection{Software}

The usual software will be used, i.e. FirstNet; however, as special Icon has been added for ChIP

\subsection{Documentation}

Two protocols have been published relating to the implementation of ChIP.

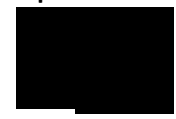

ChIP protocol (Appendix A) Link

HFNP protocol - Link

\subsection{Personnel}

Facilitators

Facilitators will be from existing staff.

Research Nurses 
Funding has been received as part of a larger project to support the implementation of ChIP from the HCF Research Foundation; some funds will be dedicated to the hiring of research nurses to support implementation.

Super users (Clinical champions)

Two super users in each area, need to have three years' experience in the area and will receive training and first preference to attend sessions. They will assist on the floor, provide guidance, help with questions.

Instructors for in-services:

- Personnel from F\&P

- ICU liaison

- Nurse educators

- Senior doctors

- Facilitators if needed

- Research nurses

\subsection{Implementation Impact}

May have some initial increased requirements on staff. This will be reduced by an allocation of research nurses and clinical champions to provide extra facilitation.

\subsection{Evaluation}

The uptake of ChIP will be measured for six - twelve months post-implementation with a fourweek gap as a buffer. This is part of a larger study and ethics will be sought. Furthermore, a second survey of staff may be done post-implementation for their evaluation if uptake levels are low.

\subsection{Glossary}

$\mathrm{BCl}$ - Blunt chest injury

ChIP - Chest Injury Protocol

ED - emergency department

HFNP - High flow Nasal Prongs

ISLHD - Illawarra Shoalhaven Local Health District

MRN - Medical record number

PT - Physiotherapist 


\section{APPENDIX A: ChIP POLICY}

1. POLICY STATEMENT

This policy describes the activation and response of a blunt chest injury pathway (ChIP), which promotes early intervention for patients who present to the Emergency Department (ED) with a blunt chest injury (proven or suspected rib fractures, or a painful chest injury)

2. AIMS

Briefly state the aim of the policy that will help people understand this procedure.

To describe the activation and response process for patients who present to the Emergency Department (ED) with a blunt chest injury.

3. TARGET AUDIENCE

Include an outline of who the policy applies to.

All clinicians who care for patients with blunt chest wall injury are responsible. In particular:

- Emergency Department (ED) medical and nursing staff

- Surgical registrars (covering ED)

- Physiotherapists

- Switch board staff

- Pain service / anaesthetics

- ICU liaison / resource nurses

\section{RESPONSIBILITIES}

Outline clearly and succinctly the precise actions that are required of those responsible for enacting this policy. Members of this team will receive a message via their page to review patients with blunt chest wall injury who meet criteria. This policy also describes the recommended treatments to tailor for each patient dependent on their needs.

1. All patients with isolated blunt chest injury (radiological or clinical diagnosis) are to be considered for this pathway

2. The role of the ED Doctor and/or nurse is to assess the patient for likelihood of injury, attend to their immediate analgesia (+/- opiates), respiratory support needs and likelihood of admission before the ChIP page is activated (see Appendix 1)

3. To activate the ChIP page call 991 or 9222 ChIP and patient MRN

4. The ChIP page will alert the on call Surgical registrar, Pain service (Anaesthetic Registrar out of hours), Trauma CNC, ICU registrar, ICU Liaison Nurse, ASET (Aged Services Emergency Team) and Physiotherapist to enable early contact and optimal management. Where possible, the patient should be assessed by the responding clinicians within 60 minutes of the page activation.

5. When the required services are not available (eg after hours), the person carrying the pager should check for ChIP calls and review the patient as a priority when next on site.

6. The emergency or surgical registrar should arrange consultations with specialist teams such as Aged Care as needed. 
7. All patients with proven or suspected rib fractures, or a painful chest injury requiring admission should be admitted under the surgical team on call.

8. A bundle of care including the following interventions should be charted, initiated and adapted for each patient according to their analgesic and respiratory support needs.

○ Patient education on deep breathing and coughing and the following treatments

○ Chest support pillow / splint (eg folded rolled towel)

- Incentive spirometry (triflow)

- Supplemental Oxygen, humidified via highflow nasal prongs - should commence at 501t/min and titrated to an $\mathrm{SpO} 2$ goal in patients with pain not well controlled by oral analgesia and/or lung disease. A haemo/pneumothorax does not exclude the use of HFNP. Management of the haemo/pneumothorax should be discussed with the admitting consultant / fellow

- Analgesic regimen: PO Paracetamol and PO Oxycodone hydrochloride with Naloxone hydrochloride (Targin) or Oxycontin regularly if no contraindications/allergies \& appropriate dose. PRN Oxycodone hydrochloride (Endone). NSAIDs should be considered in patients without contraindications

- If inadequate analgesia despite above, escalate early to pain service for PCA

- Regional anaesthesia techniques, such as an Epidural, paravertebral or intercostal block, should be considered on a case by case basis. In particular those patients with: 3 or more rib fractures and/or age greater than 55 years. Additional consideration and factors that may infer patient benefit to those with (or without) the above factors include flail segment/s, underlying lung disease, history of smoking

- Aperients and anti-emetics

- Early mobilisation as clinically appropriate

9. Patient should be admitted to a ward with HFNP capability. If the patient has increasing $\mathrm{FiO} 2$ requirements to maintain respiratory function and observations between the flags, they should have an ICU review and admission.

10. Weaning of analgesia and HFNP should be conducted on individual patient needs. The patient should be discharged when their pain is well controlled with oral analgesia, their respiratory function has been optimised and any other factors (i.e. mobility and any medical issues that may have precipitated a fall) are resolved

11. ChIP patients should be followed up by their GP within 3 days and their analgesia. Discharge letter should include instruction on this for the GP.

12. Patients and their family should be educated throughout their admission and prior to discharge on the importance of continuing with regular analgesia as prescribed, signs of deterioration and advice to represent if necessary. The following fact sheet should be provided and explained to the patient 
https://www.aci.health.nsw.gov.au/_data/assets/pdf_file/0010/294337/Fractured_Rib s_Patient_Factsheet_2015.pdf

5. DEFINITIONS

HFNP: High Flow nasal prong

Blunt chest injury: Proven or suspected rib fractures, or a painful chest injury

Bundle of care: A group of evidence based interventions administered for specific conditions

6. DOCUMENTATION

None required.

7. $\quad$ AUDIT

The activation and appropriate use of the protocol will be evaluated by a formal research project, then ongoing monitoring will be monitored by the existing trauma service quality improvement program. Regular reports are conducted, feedback is provided where appropriate

\section{REFERENCES}

1. Testerman GM. Adverse outcomes in younger rib fracture patients. South Med J. 2006;99(4):335-339.

2. Holcomb JB, McMullin NR, Kozar RA, Lygas MH, Moore FA. Morbidity from rib fractures increases after age 45. Journal of the American College of Surgeons. 2003;196(4):549-555.

3. Kent R, Woods W, Bostrom O. Fatality risk and the presence of rib fractures. Paper presented at: Annals of Advances in Automotive Medicine - 52nd Annual Scientific Conference2008.

4. Bulger EM, Arneson MA, Mock CN, Jurkovich GJ. Rib fractures in the elderly. Journal of Trauma - Injury, Infection and Critical Care. 2000;48(6):1040-1046.

5. Barnea Y, Kashtan H, Skornick Y, Werbin N. Isolated rib fractures in elderly patients: Mortality and morbidity. Canadian Journal of Surgery. 2002;45(1):43-46.

6. Elmistekawy E, Hammad AA. Isolated rib fractures in geriatric patients. Annals of Thoracic Medicine. 2007;2(4):166-168.

7. Bansidhar BJ, Lagares-Garcia JA, Miller SL. Clinical rib fractures: are follow-up chest X-rays a waste of resources? The American surgeon. May 2002;68(5):449-453.

8. Lee RB, Bass SM, Morris JA, Jr., MacKenzie EJ. Three or more rib fractures as an indicator for transfer to a Level I trauma center: a population-based study. Journal of Trauma-Injury Infection \& Critical Care. 1990;30(6):689-694.

9. Battle CE, Hutchings H, Evans PA. Risk factors that predict mortality in patients with blunt chest wall trauma: a systematic review and metaanalysis. Injury. 2012;43(1):8-17. 10. 


\section{APPENDIX 1}

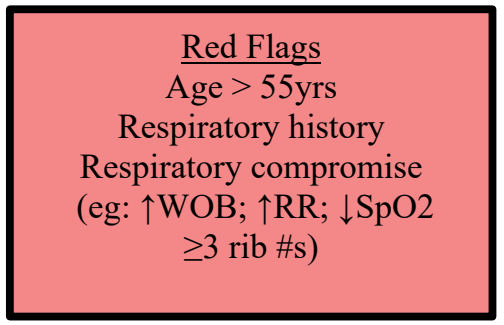

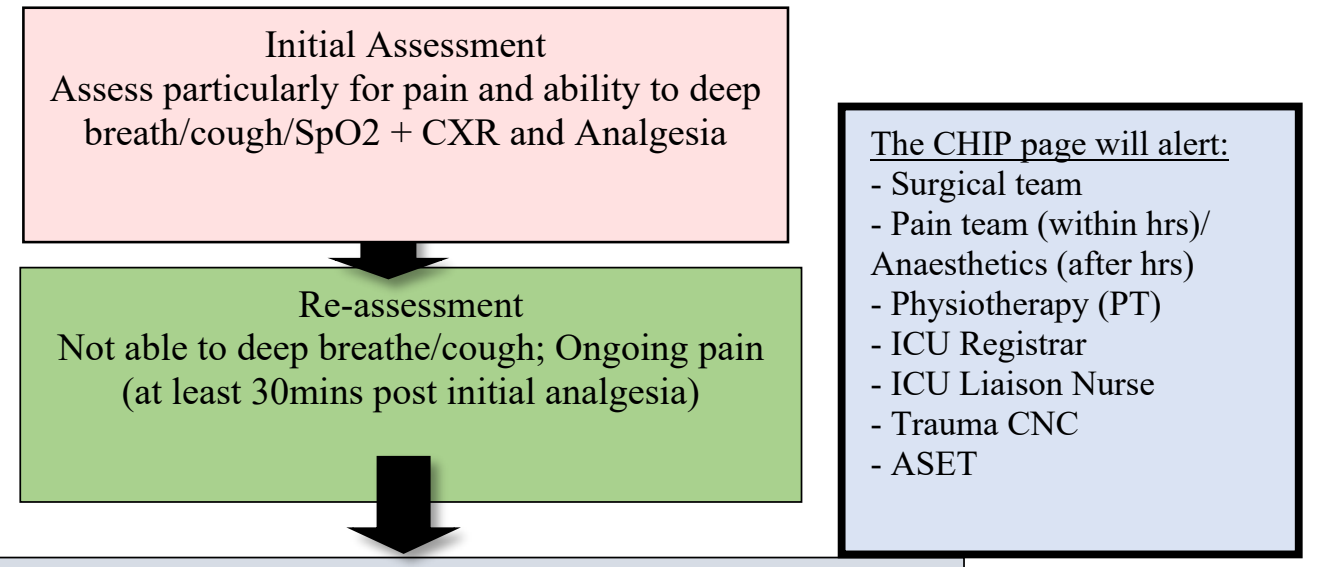

CALL 991 or 9222 (site specific)

ACTIVATE CHIP AND Provide MRN

Patient to be reviewed by on call Surgical Registrar to determine if admission is required.
Respiratory Adjuncts: Consider HFNP:

Start at 50L Flow/ Fio2 30-40\%

(Does not exclude HTx/PTx - but discuss with surg fellow)

Clearly document HFNP settings as well as $\mathrm{SpO} 2$ goal in patient's notes.
If patient for admission....

$\mathrm{AMO} 1=$ Surgery. AMO2 as appropriate (eg GenMed)

Appropriate Bed Allocation (HFNP capability +/- ICU)

\section{,}

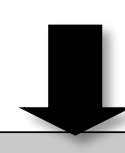

Analgesic regime:

- Oral: Targin, Paracetamol,

NSAIDs

PRN Endone

- IV: Consider PCA

- Consider IC Block/

Paravertebral Block/ Epidural

Don't forget aperients
Complication Prevention: Early Clearance to Mobilise Patient education

DB\&C

Regular and PRN analgesia Incentive spirometry Support/splint pillows

Referrals to consider prior to transfer:

Low threshold for ICU admission. GenMed if needed

Discharge Planning from ward:

Wean HFNP/Analgesia (per patient condition)

Discharge home when pain well controlled \& respiratory function optimised

Patient / family education to include return to ED if breathing or pain worsens

GP f/u within 3 days 


\section{APPENDIX B: Stakeholders*}

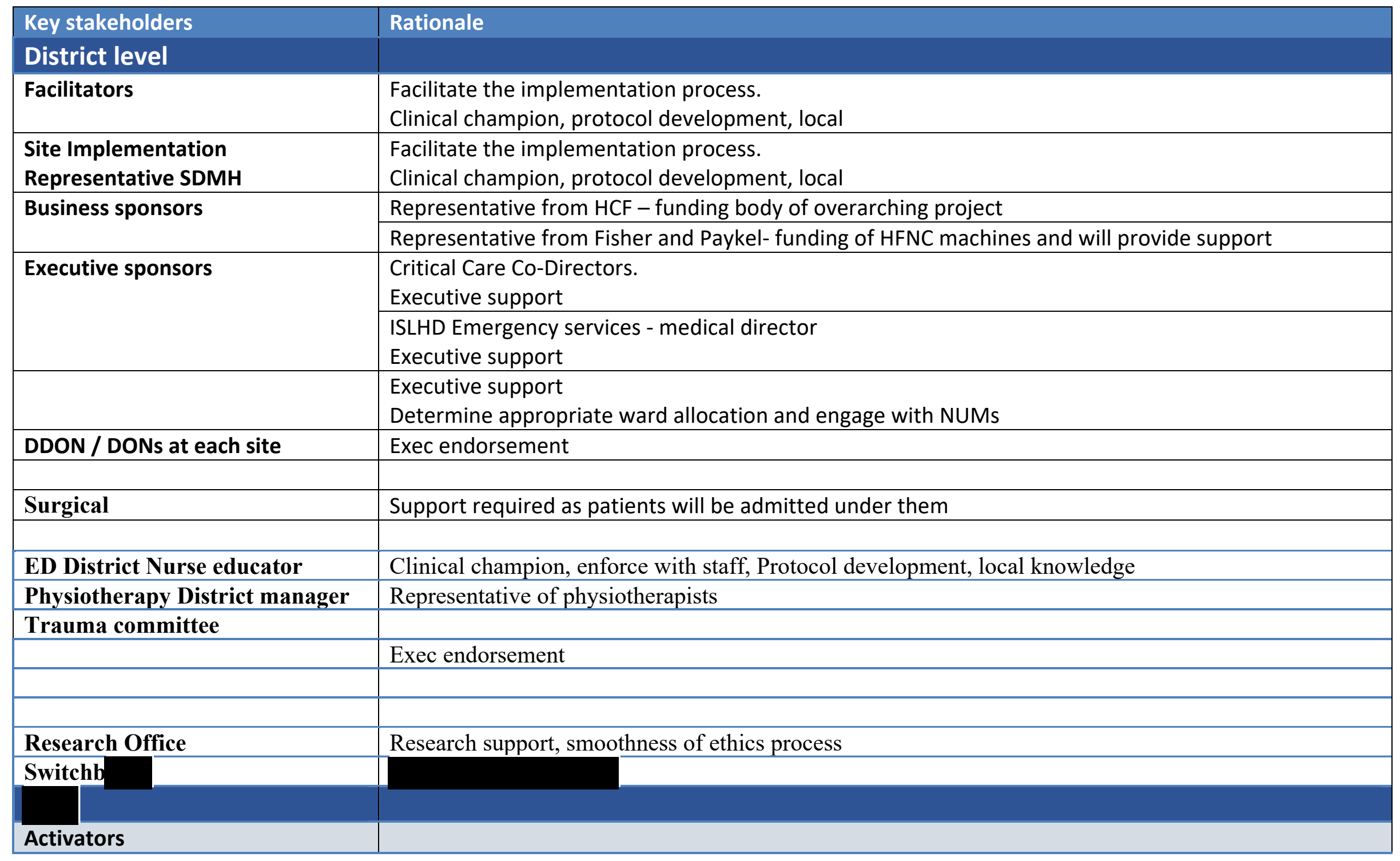




\begin{tabular}{|c|c|}
\hline ED Director & Clinical champion, enforce with staff \\
\hline \multicolumn{2}{|l|}{ ED medical staff } \\
\hline ED NUM & Clinical champion, enforce with staff \\
\hline ED Clinical NUM / patient flow & Clinical champion, enforce with staff, Protocol development, local knowledge \\
\hline \multicolumn{2}{|l|}{ ED CNC } \\
\hline ED CNE & Clinical champion, enforce with staff \\
\hline \multicolumn{2}{|l|}{ ED nursing staff } \\
\hline \multicolumn{2}{|l|}{ Responders } \\
\hline \multicolumn{2}{|l|}{ Surgeons } \\
\hline Anaesthetics / pain team & Patients will be reviewed by them (in and out of hours). Need agreement \\
\hline Physiotherapy manager & Support required as patients will be reviewed by them \\
\hline ICU Director & Support required as patients will potentially be reviewed by them \\
\hline $\begin{array}{l}\text { ICU liaison nurse / Clinical } \\
\text { Resource nurse / ICU NUM }\end{array}$ & Patient should be reviewed by them \\
\hline \multicolumn{2}{|l|}{ Support } \\
\hline \multicolumn{2}{|l|}{ DON } \\
\hline \multicolumn{2}{|l|}{ ED equipment officer } \\
\hline \multicolumn{2}{|l|}{ Switch board } \\
\hline \multicolumn{2}{|l|}{ Trauma service } \\
\hline Bed managers / AH & Appropriate bed allocation \\
\hline CNC for surgery & Patient should be reviewed by them \\
\hline \multicolumn{2}{|l|}{ Ward NUMs } \\
\hline \multicolumn{2}{|l|}{ Activators } \\
\hline ED Director & Clinical champion, enforce with staff \\
\hline
\end{tabular}




\begin{tabular}{|c|c|}
\hline ED NUM & Clinical champion, enforce with staff \\
\hline \multicolumn{2}{|l|}{ ED medical staff } \\
\hline \multicolumn{2}{|l|}{ ED CNC } \\
\hline \multicolumn{2}{|l|}{ ED CNE } \\
\hline \multicolumn{2}{|l|}{ ED nursing staff } \\
\hline ED Clinical NUM / patient flow & Clinical champion, enforce with staff, Protocol development, local knowledge \\
\hline \multicolumn{2}{|l|}{ Responders } \\
\hline Surgery & Support required as patients will be admitted under them \\
\hline \multicolumn{2}{|l|}{ Anaesthetics / Pain team } \\
\hline Physiotherapy & Support required as patients will be reviewed by them \\
\hline ICU & Support required as patients will potentially be reviewed by them \\
\hline \multicolumn{2}{|l|}{ Support } \\
\hline \multicolumn{2}{|l|}{ DON } \\
\hline \multicolumn{2}{|l|}{ ED equipment officer } \\
\hline Switch board & Support Implementation \\
\hline Trauma service & N/A \\
\hline Bed managers / AH & Appropriate bed allocation \\
\hline Ward NUMs & \\
\hline
\end{tabular}

*Columns with names, contact details and status have been removed to protect confidentiality. 


\section{APPENDIX C: References}

Harvey, G., \& Kitson, A. (2016). PARIHS revisited: from heuristic to integrated framework for the successful implementation of knowledge into practice. IMPLEMENTATION SCIENCE, 11(1), 33. doi:10.1186/s13012-016-0398-2

Michie, S., van Stralen, M. M., \& West, R. (2011). The behaviour change wheel: a new method for characterising and designing behaviour change interventions. Implementation science : IS, 6(1), 42-42. doi:10.1186/1748-5908-6-42

Rycroft-Malone, J. (2004). The PARIHS framework - A framework for guiding the implementation of evidence-based practice. Journal of Nursing Care Quality, 19(4), 297-304. doi:10.1097/00001786-200410000-00002

Stetler, C. B., Damschroder, L. J., Helfrich, C. D., \& Hagedorn, H. J. (2011). A Guide for applying a revised version of the PARIHS framework for implementation. Implementation science : IS, 6(1), 99-99. doi:10.1186/1748-5908-6-99 